\title{
A dynamical systems analysis of afferent control in a neuro-mechanical model of locomotion
}

\author{
Lucy Spardy ${ }^{1 *}$, Sergey Markin², Boris Prilutsky ${ }^{3}$, llya Rybak², Jonathan Rubin ${ }^{1}$ \\ From Nineteenth Annual Computational Neuroscience Meeting: CNS*2010 \\ San Antonio, TX, USA. 24-30 July 2010
}

Existing models have represented a locomotor system as a rhythmic driver, or central pattern generator (CPG), coupled to a mechanical limb, with feedback closing the loop. Our collaborators have developed a version of this model in which the CPG establishes a rhythm when activating drive is present, and feedback from ground strike helps control phase switching and rhythm stabilization. Spinal cord injury can be simulated through termination of drive, which ceases the rhythm. We derive and analyze a reduced representation of this model, which will elucidate general principles of phase and frequency control in normal locomotion. We aim to understand how the presence of feedback provides stable locomotion, allowing oscillations at a wider range of drive values to the CPG (specifically at lower values) than the CPG without afferent feedback. Furthermore, increasing the drive intensity to the CPG increases locomotor speed by reducing only the duration of the stance phase, at a relatively constant duration of swing phase [1]. This phase asymmetry has been seen in normal locomotion in cats, rats, and humans, but is not observed in the locomotor model without feedback, so we analyze how feedback facilitates this asymmetry. We will also reveal sufficient conditions for recovering rhythmicity in the injured state - how in the absence of drive, increased feedback can restore locomotion and contribute to locomotor stability, with an analysis of differences in rhythm robustness before and after loss of drive.

\section{Author details}

'Department of Mathematics, University of Pittsburgh, Pittsburgh, PA 15213, USA. ${ }^{2}$ Department of Neurobiology and Anatomy, Drexel University College of Medicine, Philadelphia, PA 19129, USA. ${ }^{3}$ Center for Human Movement Studies, Georgia Institute of Technology, Atlanta, GA 30332, USA.

\footnotetext{
* Correspondence: les65@pitt.edu

'Department of Mathematics, University of Pittsburgh, Pittsburgh, PA 15213, USA
}

Published: 20 July 2010

Reference

1. Markin S, Klishko A, Shevtsova N, Lemay M, Prilutsky B, Rybak I: Afferent control of locomotor CPG: Insights from a simple neuro-mechanical model. Cellular and Network Functions in the Spinal Cord, Annals of the New York Academy of Sciences J. Fetcho, S. Hochman, A. McDermott, P. Stein, and L. Ziskind-Conhaim 2010.

doi:10.1186/1471-2202-11-S1-P19

Cite this article as: Spardy et al:: A dynamical systems analysis of afferent control in a neuro-mechanical model of locomotion. BMC Neuroscience 2010 11(Suppl 1):P19.
Submit your next manuscript to BioMed Central and take full advantage of:

- Convenient online submission

- Thorough peer review

- No space constraints or color figure charges

- Immediate publication on acceptance

- Inclusion in PubMed, CAS, Scopus and Google Scholar

- Research which is freely available for redistribution

Submit your manuscript at www.biomedcentral.com/submit
C Biomed Central 